\title{
CAPÍTULO 05: PROTEASES E SUAS APLICAÇÕES BIOTECNOLÓGICAS NAS INDÚSTRIAS ALIMENTÍCIAS
}

\section{CAPÍTULO 05: PROTEASAS Y SUS APLICACIONES BIOTECNOLÓGICAS EN LAS INDUSTRIAS ALIMENTARIAS}

\section{CHAPTER 05: PROTEASES AND THEIR BIOTECHNOLOGICAL APPLICATIONS IN THE FOOD INDUSTRIES}

\author{
Maria Clara do Nascimento ${ }^{1}$; Viviane do Nascimento e Silva Alencar ${ }^{2}$; Thiago Pajeú Nascimento ${ }^{3}$; Juanize \\ Matias da Silva Batista ${ }^{4}$ Ana Lúcia Figueiredo Porto ${ }^{5}$
}

DOI: https://doi.org/10.31692/978-65-88970-19-5.63-82

\begin{abstract}
RESUMO
Enzimas são proteínas capazes de acelerar reações químicas e podem ser organizadas em seis classes de acordo com seu sítio ativo. Na Classe 3 estão as proteases, enzimas que atuam na hidrólise de ligações peptídicas e indispensáveis na coagulação, digestão de alimentos e até mesmo o melhoramento de produtos industrializados, como em detergentes, medicamentos e couro por exemplo. Por agir em muitas reações, as proteases se tornam uma grande aliada das indústrias de alimentos que utilizam essas enzimas para otimizarem seus produtos, modificando seu sabor, cor, forma, textura ou até mesmo a funcionalidade nutricional. O objetivo desta revisão é descrever características das proteases e o modo como elas são aplicadas em alguns ramos da indústria de alimentos. No setor de carnes as proteases são frequentemente utilizadas no amaciamento de carnes, sua ação de ocorre na degradação de proteínas presentes em todo o sistema conjuntivo. Autores afirmaram a eficiência de proteases de origem vegetal sobre as miofibrilas e o sarcômero carne de frango e de bacteriana de carne bovina. Para a produção de queijos as proteases são peças fundamentais na etapa de coagulação do leite para que ocorra normalmente o processo de fabricação. Na panificação o uso de proteases é bastante voltado para a degradação do glúten proteína que concede dureza a massa, foi constatado que seu uso aumenta a viscosidade da massa, diminui a dureza, melhora a textura e o sabor do produto. Já na indústria cervejeira as enzimas com atividade proteolítica são utilizadas para deixar o produto menos turvo, ou seja, na clarificação, na maturação do sabor e até mesmo na quantidade de espumas formadas pela bebida. Pesquisadores também testaram o uso de proteases na gradação do glúten presente na cerveja e constataram que a enzima foi capaz de diminuir o teor de glúten. Os dados observados demonstram que as proteases são bastante eficazes quando aplicadas em alimentos, suas propriedades podem agir em vários aspectos do produto levando a inovações, mudanças, melhoramentos e agregação de valores.
\end{abstract}

Palavras-chave: Peptidases, Biotecnologia, Indústrias de alimentos e bebidas.

\section{RESUMEN}

Las enzimas son proteinas capaces de acelerar reacciones químicas, según su acción durante estas reacciones, las enzimas se organizan en seis clases. En la Clase 3 se encuentran las proteasas, enzimas capaces que poseen características que les permiten ser útiles en diversos eventos como la coagulación, digestión de alimentos e incluso la mejora de productos industrializados, como detergentes, medicamentos y cuero por ejemplo. Al actuar en muchas reacciones, las proteasas se convierten en un gran aliado de las industrias alimentarias que utilizan estas enzimas para optimizar sus productos, cambiando su sabor, color, forma, textura o incluso funcionalidad nutricional. Algunos de los principales sectores de la industria alimentaria que utilizan proteasas durante el proceso de fabricación de sus

\footnotetext{
1 Bacharelado em Ciências Biológicas, Universidade Federal Rural de Pernambuco, mclaranaascimento@hotmail.com

${ }^{2}$ Mestra em Ciências da Saúde, Universidade Federal de Pernambuco, viviane.ntosilva@gmail.com

${ }^{3}$ Doutor em Biologia Aplicada a Saúde, Universidade Federal de Pernambuco, thiago_pajeu@ hotmail.com

${ }^{4}$ Doutora em Biociência Animal, Universidade Federal Rural de Pernambuco, juanizematias@ yahoo.com.br

${ }^{5}$ Professora Titular, Universidade Federal Rural de Pernambuco, analuporto@ yahoo.coom.br
} 
productos son los lácteos, carnes, cervezas y en panadería. El propósito de esta revisión es describir las características de las proteasas y cómo se aplican en algunas ramas de la industria alimentaria. En el sector cárnico, las proteasas se utilizan a menudo en el ablandamiento de la carne, su acción se produce en la degradación de las proteínas presentes en todo el sistema conjuntivo. Los autores afirman la eficacia de las proteasas de origen vegetal sobre las miofibrillas y la carne de pollo sarcómera y de las bacterias de la carne bovina. Para la producción de queso, las proteasas son partes esenciales en la etapa de coagulación de la leche para que el proceso de fabricación ocurra normalmente. En horneado, el uso de proteasas está muy enfocado a la degradación de la proteína del gluten que le da a la masa su dureza, se encontró que su uso aumenta la viscosidad de la masa, disminuye la dureza, mejora la textura y sabor del producto. En la industria cervecera se utilizan enzimas con actividad proteolítica para hacer el producto menos turbio, es decir, en la clarificación, en la maduración del sabor e incluso en la cantidad de espumas formadas por la bebida. Los investigadores también probaron el uso de proteasas en la clasificación del gluten presente en la cerveza y encontraron que la enzima podía disminuir el contenido de gluten. Los datos observados demuestran que las proteasas son bastante efectivas cuando se aplican a los alimentos, sus propiedades pueden actuar en varios aspectos del producto dando lugar a innovaciones, cambios, mejoras y agregación de valores.

Palabras Clave: Peptidasas, Biotecnología, Industrias de alimentos y bebidas.

\begin{abstract}
Enzymes are proteins capable of accelerating chemical reactions, according to their action during these reactions, enzymes are organized into six classes. In Class 3 are proteases, capable enzymes that have characteristics that allow them to be useful in various events such as coagulation, food digestion and even the improvement of industrialized products, such as detergents, medicines and leather for example. By acting in many reactions, proteases become a great ally of the food industries that use these enzymes to optimize their products, changing their taste, color, shape, texture or even nutritional functionality. Some of the main sectors of the food industry that use proteases during the manufacturing process of their products are dairy products, meats, beers and in bakery. The purpose of this review is to describe characteristics of proteases and how they are applied in some branches of the food industry. In the meat sector, proteases are often used in meat tenderization, their action occurs in the degradation of proteins present in the entire conjunctive system. Authors affirmed the efficiency of proteases of vegetal origin on the myofibrils and the sarcomere chicken meat and of bacterial of bovine meat. For cheese production, proteases are essential parts in the milk coagulation stage so that the manufacturing process normally occurs. In baking, the use of proteases is very focused on the degradation of the gluten protein that gives the dough its hardness, it was found that its use increases the viscosity of the dough, decreases the hardness, improves the texture and flavor of the product. In the brewing industry, enzymes with proteolytic activity are used to make the product less cloudy, that is, in clarification, in the maturation of the flavor and even in the amount of foams formed by the drink. Researchers also tested the use of proteases in the grading of gluten present in beer and found that the enzyme was able to decrease the gluten content. The observed data demonstrate that proteases are quite effective when applied to foods, their properties can act in several aspects of the product leading to innovations, changes, improvements and aggregation of values.
\end{abstract}

Keywords: Peptidases, Biotechnology, Food and beverage industries.

\title{
INTRODUÇÃO
}

Enzimas são proteínas especializadas cuja função é principalmente a catálise de reações. As enzimas podem ser proteínas específicas, nas quais uma das suas funções é a catálise de reações, portanto, essa propriedade torna as enzimas alvo de diversos estudos para sua aplicação em indústrias de diferentes setores. Dentre as enzimas de maior interesse comercial, as proteases, também chamadas de peptidases ou proteinases que tem como principal função de 
catálise em reações de clivagem de proteínas, atuando nas suas ligações peptídicas e agindo por meio da hidrólise. Essas enzimas no organismo estão envolvidas em vários processos como a digestão de alimentos, ativação de outras enzimas, coagulação sanguínea e também o transporte de proteínas através da membrana. Algumas características das proteases podem as classificálas em diferentes grupos, essas características incluem: sob qual $\mathrm{pH}$ a atividade da protease se expressa melhor, as substâncias presentes em seu sítio ativo, em quais tipos de ligações químicas ou em qual local da ligação irão ocorrer as clivagens realizadas por cada protease. Por estarem presentes em vários eventos biológicos, as proteases podem ser encontradas em inúmeros organismos (KERMASHA \& ESKIN, 2021).

As fontes das proteases podem ser diversas, como, plantas, animais e microrganismos. Em plantas geralmente essas enzimas se encontram no látex e nas sementes dos vegetais. Che et al., (2021) detectou a presença as proteases do tipo endopeptidases aspárticas e serina carboxipeptidases na semente de Sesamum indicum, o gergelim e sua ação na degradação das proteínas presentes na soja, amendoim, leite bovino e até mesmo do próprio gergelim. Em animais podem ser encontradas dentro do seu organismo ou no caso de animais peçonhentos elas estão presentes em suas peçonhas. A víbora Echis pyramidum endêmica no nordeste da África e na Península Arábica possui um veneno que pode desencadear diversas problemáticas na saúde de um indivíduo como, a desregulação na coagulação sanguínea, a formação de edemas e a perda excessiva de sangue que pode levar a morte, todos esses efeitos são potencialmente estimulados devido a presença de proteases no veneno, isso levou El-Yamany e colaboradores (2020) a investigarem a desintoxicação do veneno através da aplicação de raios gama sobre as metaloproteases presentes na peçonha, ao final da pesquisa os autores constataram grande sucesso no uso das metaloproteases produzidas pela víbora como antídoto contra o veneno de Echis pyramidum. A produção de proteases por microrganismos é bem diferente das demais, a produção acontece a partir de biotransformações realizadas durante o bioprocesso. Um estudo recentemente publicado pelos autores Mukhia, Kumar, A. e Kumar, R. (2021) demonstrou que as proteases extracelulares produzidas pela bactéria gram-negativa Chryseobacterium polytrichastri conseguiram hidrolisar as proteínas presentes soja levando a obtenção de peptídeos com grande ação antioxidantes que quando integrados na dieta proporcionam diversos benefícios a saúde além daqueles proporcionados por seus valores nutricionais.

Comparando as três fontes de proteases, a microbiana se torna a mais interessante por ser mais vantajosa por apresentar uma produção rápida, numerosa e de baixo custo (HARISH \& UPPULURI, 2018; RAZZAQ et al., 2019; TAVANO et al., 2018). Essa propriedade 
biológica permitiu que estudiosos utilizassem as peptidases em vários setores industriais como

em fármacos, formulação de detergentes, indústrias de couro, cervejaria e alimentos. $\mathrm{Na}$ indústria alimentícia, as proteases possuem uma gama de utilidades devido a sua capacidade de alterar diversas propriedades dos alimentos como a solubilidade, teor de emulsificação, interações peptídicas, formação de espuma, sabor e textura, logo, por esses motivos as indústrias alimentícias são as maiores consumidoras de enzimas comerciais (GRAND VIEW RESEARCH, 2019; TAVANO et al., 2018).

Portanto, com a expansão do conhecimento sobre as propriedades das proteases ocorre um crescimento no número de estudos sobre suas aplicações em laboratórios visando sua aplicação em escala industrial, gerando diferentes pesquisas nos mais variados setores alimentícios. Dessa forma, o objetivo desta revisão é descrever algumas propriedades das proteases, como ocorre a sua ação nos alimentos em que estão presentes e a discussão de algumas pesquisas correlacionadas ao assunto.

\section{FUNDAMENTAÇÃO TEÓRICA}

\section{Enzimas}

Enzimas são moléculas orgânicas que realizam reações de catalização ocorrendo alteração na velocidade de uma reação química. Elas são essenciais ao funcionamento dos organismos vivos, estão envolvidas em atividades que mantêm o equilíbrio do indivíduo tais como a digestão, produção e gasto de energia, crescimento celular, equilíbrio hormonal e outros. As enzimas são constituídas por proteínas o que as fazem ter uma estrutura rica e complexa, mas mesmo sendo tão completa em alguns momentos as enzimas necessitam do auxílio de outras substâncias para poderem realizar suas ações, essas são conhecidas como coenzimas (componentes químicos) e cofatores (componentes orgânicos). A quantidade de enzimas já descobertas é enorme o que como várias outras substâncias levou a necessidade de uma classificação, apesar de terem em suas estruturas proteínas e aminoácidos as enzimas foram classificadas de acordo com sua ação, o que levou a criação de seis classes de enzimas, sendo elas: Classe 1 (oxidorredutases), Classe 2 (transferases), Classe 3 (hidrolases), Classe 4 (liases), Classe 5 (isomerases) e Classe 6 (ligases). Na nomenclatura das enzimas ocorre muito a ambiguidade pelo fato de enzimas diferentes serem capazes de executar as mesmas ações, isso levou a uma nomenclatura mais detalhada onde a enzima deve ter um número "EC" determinado pela Enzyme Commission, ao total o nome da enzima terá quatro números: o 
número de sua classe, o número de sua subclasse, o número de sua sub-sub-classe e seu número

específico, e ao final a nomenclatura da enzima ficará "EC A.B.C.D” (ENZYME, 2021; NELSON E COX, 2018).

\section{Proteases}

Como supracitado na Classe 3 das enzimas estão as hidrolases (EC 3.b.c.d), seu prefixo "hidro" foi definido por enzimas atuarem através de hidrólise, onde a presença de uma ou mais moléculas de água $\left(\mathrm{H}_{2} \mathrm{O}\right)$ irão desencadear a quebra de outras moléculas. Elas estão presentes em vários eventos biológicos, como por exemplo na produção de glicose, onde durante a glicogênese uma enzima que catalisa a hidrólise de ésteres de fosfato (glicose-6-fosfatase) realiza a desfosforilação da Glicose-6-fosfato convertendo-a em uma molécula de fosfato e outra de glicose (Figura 01) (RODWELL et al., 2021). Por sua vez as hidrolases são separadas em subclasses, a classificação ocorre de acordo sobre qual ligação química sua ação irá ocorrer, essa separação levou a origem de doze subclasses de hidrolases, como pode ser visto na Tabela 01 (ENZYME, 2021).

Figura 01: Mecanismo de ação de uma hidrolase onde ocorre a conversão da Glicose-6-fosfato em moléculas distintas de Fosfato inorgânico e Glicose.

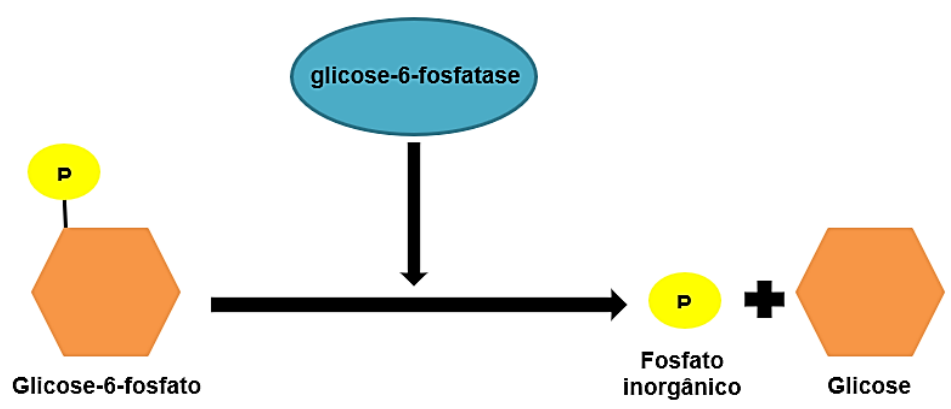

Fonte: Própria (2021). 


\begin{tabular}{cc}
\hline Subclasse & Local de atuação \\
\hline 3.1 & Ligações éster \\
\hline 3.2 & Glicosilases \\
\hline 3.3 & Ligações éter \\
\hline $\mathbf{3 . 4}$ & Ligações peptídicas \\
\hline 3.5 & Ligações carbono-nitrogênio \\
\hline 3.6 & Anidridos ácidos \\
\hline 3.7 & Ligações carbono-carbono \\
\hline 3.8 & Ligações halogenadas \\
\hline 3.9 & Ligações fósforo-nitrogênio \\
\hline 3.10 & Ligações enxofre-nitrogênio \\
\hline 3.11 & Ligações carbono-fósforo \\
\hline 3.12 & Ligações enxofre-enxofre \\
\hline 3.13 & Ligações carbono-enxofre \\
\hline
\end{tabular}

Fonte: Adaptado de Enzyme, apenas para fins ilustrativos (2020).

$\mathrm{Na}$ subclasse 3.4 das hidrolases estão presentes enzimas que atuam sobre ligações peptídicas, dentro desse grupo estão as proteases (EC 3.4.---) enzimas que capazes de hidrolisar as ligações peptídicas entre os aminoácidos presentes nas proteínas (Figura 02a). Essas são subdivididas em dois grandes grupos de acordo com o local de sua ação, quando a quebra da ligação entre os aminoácidos ocorre na extremidade N-terminal (aminopeptidases) ou Cterminal (carboxipeptidases) (Figura 02c) as proteases são classificadas como exopeptidases (EC 3.4.11.- até EC 3.4.19.-), quando a ação ocorre sobre ligações peptídicas internas (Figura 02b) as proteases são denominadas endopeptidases (EC 3.4.21.- até EC 3.4.99.-) (ÂNGELO, 2010). Outra classificação dentro do grupo das proteases é realizada de acordo com as substâncias presentes em seu sítio ativo (local onde ocorre a reação enzimática), levando essa característica em consideração, o banco de dados exclusivo de proteases MEROPS, classifica as proteases entre as famílias: aspártico $(\mathrm{A})$, cisteína $(\mathrm{C})$, glutâmico $(\mathrm{G})$, metalo $(\mathrm{M})$, asparagina (N), misto (P), serina (S), treonina (T) e desconhecido (U) (MEROPS, 2019; MURI, 2014). Além dessas classificações as proteases podem ainda serem divididas de com o seu pH ótimo, onde teremos as proteases ácidas, neutras e alcalinas. 
Figura 02: A - Representação de uma molécula de glúten; B - Hidrólise do glúten realizada por endopeptidases; C - Clivagem do glúten realizada por exopeptidases.
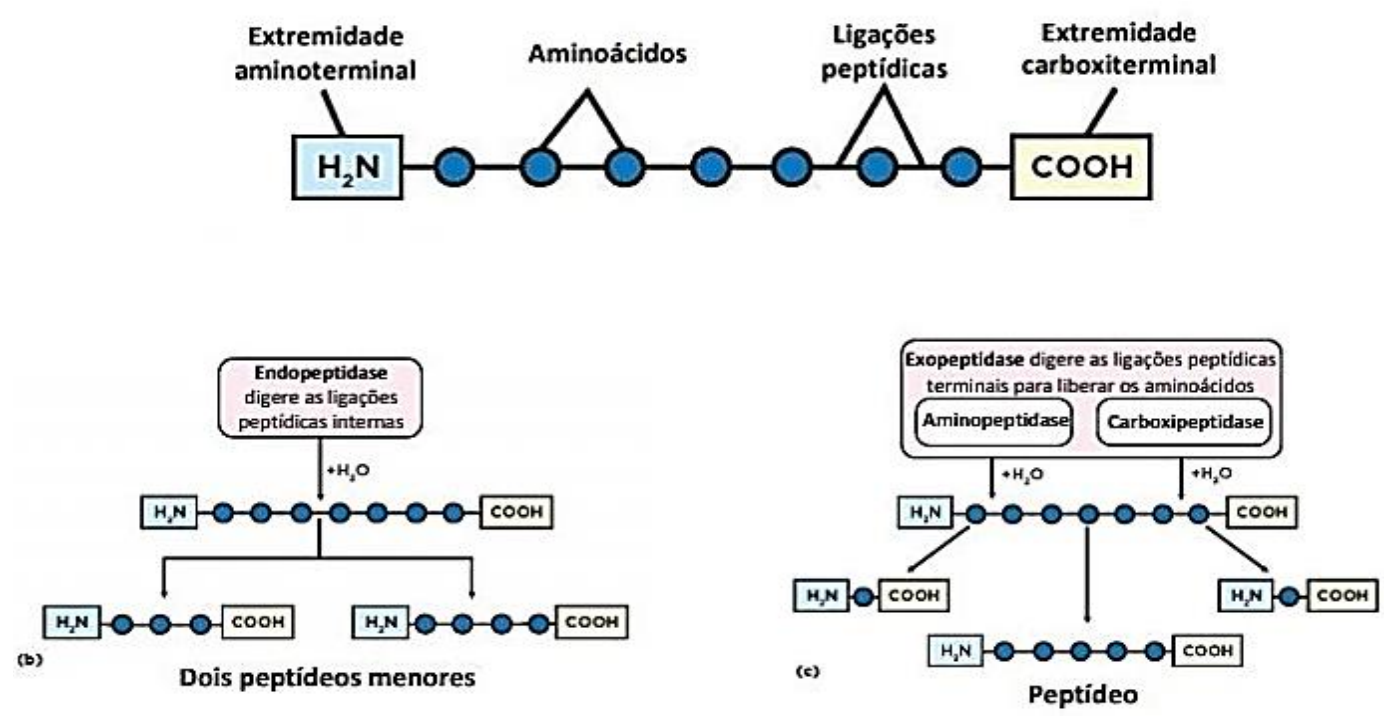

Fonte: Boa fórmula, 2020.

As proteases são enzimas que estão presentes em diversos seres vivos, elas podem ser produzidas por animais, vegetais e até mesmo por microrganismos. Como as proteases estão presentes em vários eventos biológicos, as proteases de origem animal e vegetal geralmente se encontram nos organismos dos indivíduos ou em produtos gerados por eles. Nos animais, podemos encontrar proteases nas peçonhas de serpentes, no corpo de crustáceos e no trato digestivo de peixes (LIU et al., 2019; NEUMANN et al., 2020; OLIVEIRA et al., 2020).

A utilização de animais como fontes de proteases pode sofrer desvantagens caso seja necessário o sacrifício do animal e consequentemente a necessidade do aval de comitês de éticas para obtenção da enzima, porém essa fonte pode ser a solução para o uso de resíduos sólidos gerados por algumas indústrias como o mercado da pesca, já que a estudos demonstram o uso das vísceras de peixes como fonte de proteases (SILVA et al., 2021). Várias proteases já foram encontradas, extraídas e utilizadas a partir do sistema digestivo de animais, entre elas a pepsina, a tripsina e a quimiotripsina (GURUMALLESH et al., 2019).

Em plantas, as proteases geralmente são detectadas em seus "produtos" como as sementes e o látex. Para a extração dessas enzimas em plantas é necessário mão de obra específica para o manejo e também a dependência de fatores ambientais como o clima, umidade, temperatura e sazonalidade temporal o que leva a processos de extração mais longos, trabalhosos e dependentes (MUSIDLAK et al., 2020; SILVA et al., 2020).

Diante dessas características sobre a obtenção de proteases a partir de animais e plantas, os microrganismos demonstram ser a fonte mais econômica e rápida. A produção de compostos 
bioativos, como as proteases, por microrganismos se dá através de processos fermentativos em

que geralmente há apenas a necessidade de um substrato e condições favoráveis ao crescimento do organismo e a produção de biomoléculas, o que pode facilmente ser controlado durante a fermentação. Ao realizar uma breve pesquisa em bancos de dados científicos, foi observado que cientistas já produziram proteases a partir de fungos, bactérias e cianobactérias (ELLEUCH et al., 2021; OSMOLOVSKIY et al., 2021; SHAFIQUE et al., 2021). Alguns organismos produtores de proteases pertencentes as três fontes supracitadas, estão descritas na Tabela 02.

Tabela 02: Organismos já utilizados como fontes de proteases.

\begin{tabular}{|c|c|c|c|}
\hline Fonte & Produtores & Classificação & Referências \\
\hline \multirow{6}{*}{ Microrganismos } & Arthrospira sp. & Cisteíno Protease & ELLEUCH et al., 2021 \\
\hline & Aspergillus sp. & Protease Ácida & $\begin{array}{c}\text { CHIMBEKUJWO, } \\
\text { JA'AFARU \& ADEYEMO, } \\
2021\end{array}$ \\
\hline & Bacillus sp. & Serina protease & YANG et al., 2021 \\
\hline & Penicillium sp. & Protease aspártica & GUO et al., 2021 \\
\hline & Pseudomonas sp. & Serina protease & IQBAL et al., 2018 \\
\hline & Streptomyces sp. & Protease alcalina & $\begin{array}{c}\text { SARKAR \& } \\
\text { SUTHINDHIRAN, } 2020\end{array}$ \\
\hline \multirow{6}{*}{ Animais } & Bothrops sp. & Serina protease & KUNIYOSHI et al., 2019 \\
\hline & Centropomus sp. & $\begin{array}{l}\text { Serina protease e } \\
\text { Metaloprotease }\end{array}$ & LÓPEZ et al, 2021 \\
\hline & Cupiennius sp. & Serina protease & $\begin{array}{l}\text { LANGENEGGER } \text { et al., } \\
2018\end{array}$ \\
\hline & Echis sp. & Metaloprotease & EL-YAMANY et al., 2021 \\
\hline & $\begin{array}{l}\text { Macrobrachium } \\
\text { sp. }\end{array}$ & Exopeptidase & SILVA et al., 2020 \\
\hline & Cichla sp. & Serina protease & OLIVEIRA et al., 2020 \\
\hline \multirow{5}{*}{ Plantas } & Calotropis sp. & Cisteíno protease & SILVA et al., 2020 \\
\hline & Gliricidia sp. & Cisteíno protease & SILVA et al., 2020 \\
\hline & Euphorbia sp. & Serina protease & URS et al., 2021 \\
\hline & Moringa sp. & $\begin{array}{c}\text { Serina e Cisteíno } \\
\text { protease }\end{array}$ & WANG et al., 2020 \\
\hline & Solanum sp. & Protease aspártica & IBAÑNZZ et al., 2021 \\
\hline
\end{tabular}

\section{Aplicações biotecnológicas das proteases}

Devido a suas atividades e propriedades, as proteases ou peptidases, como também podem ser definidas, foram as primeiras enzimas a serem exploradas economicamente. A empresa americana especialista em consultoria e pesquisa de mercado, Grand View Research, publicou um relatório em 2019 no qual estimou-se que o mercado mundial de enzimas atingiu 
a partir de 2020, e com previsão para até 2027 de US\$14,9 bilhões. As enzimas chegam atingir

até $60 \%$ de uso entre as indústrias, são utilizadas nos mais diversos setores, as proteases por sua vez estão presentes nos mais variados ramos industriais, como: na indústrias de alimentos durante o amaciamento de carnes; em indústria farmacêutica no desenvolvimento de medicamentos; na indústria de produtos limpeza como na potencialização de detergentes; na indústria de couros durante de remoção de pelos; no ramo da estética como no procedimento peeling (PATYSHAKULIYEVA, 2021).

O relatório da Grand View Research, que estudou a aplicação de enzimas em vários ramos industriais, também demonstrou que entre tais indústrias, as que mais fazem uso de enzimas são as indústrias bebidas e alimentos (Figura 03).

Figura 03: Gráfico representando a utilização de enzimas por diversas indústrias.

\section{U.S. industrial enzymes market size, by application, 2016 - 2027 (USD Billion)}

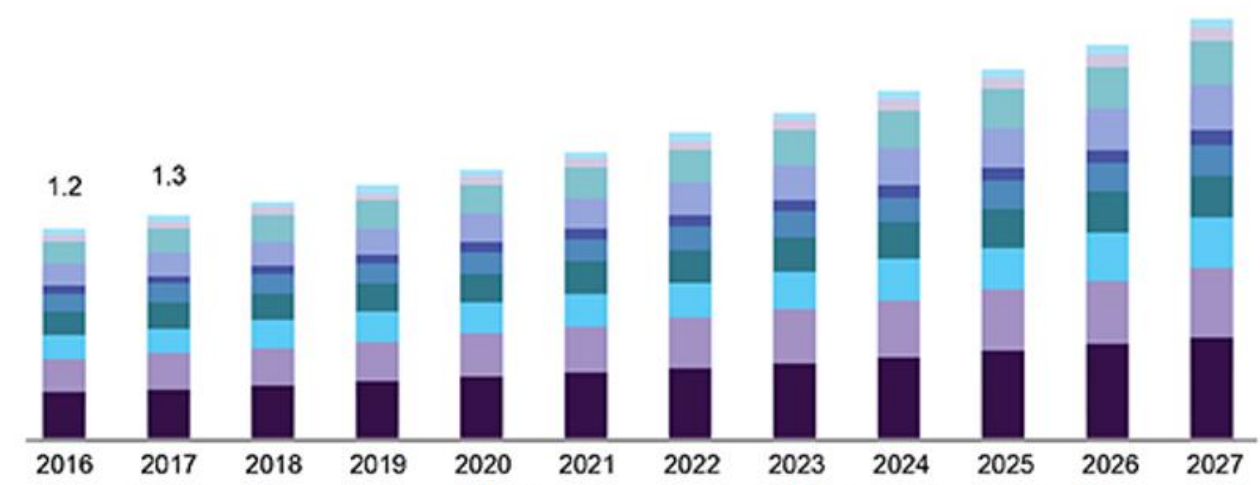

- Alimentos e bebidas Detergentes Alimentação animal Biocombustíveis Têxteis Papel de celulose Nutrição e farmácia cosméticos e cuidados pessoais Esgoto Outros

Fonte: Adaptado de Grand View Research, 2019.

A indústria alimentícia protagoniza uma incessante, e até mesmo necessária, busca por inovações e melhorias em seus produtos. Muitas das soluções biotecnológicas alcançadas, como a melhoria do sabor e aspectos de produtos nos setores de carnes e queijos, envolvem a aplicação de proteases que são utilizadas em diversas funções a fim de melhorar aroma, o sabor, a funcionalidade do produto, a textura e a sua qualidade nutricional. Entre os mais diversos produtos das indústrias alimentícias as proteases são aplicadas em laticínios, bebidas alcoólicas, molhos, sementes, massas, rações animais e outros (SILVA et al., 2017). 
Para a construção dessa revisão descritiva foram realizadas pesquisas nos bancos de dados científicos Scienc Direct e Scielo. Para o desenvolvimento do trabalho foram feitas pesquisas distintas dos descritores: enzymes, enzyme application, proteases, protease application, food industry and food biotechnology. A procura de artigos foi realizada fazendo combinações de descritores, sendo eles: [protease] and [cheese], [protease] and [beef], [protease] and [bread making], [protease and beer] e [protease] and [application] and [food or drink]. As obras publicadas de 2010 a 2021 e que mais se encaixavam com a temática da revisão foram selecionadas e descritas.

\section{RESULTADOS E DISCUSSÃO}

\section{Carnes}

No mercado de carnes a aplicação de proteases se torna comum quando o objetivo é a modificação da textura e sabor da carne, principalmente pelo interesse de agregar valores às peças de carnes que possuem pequenos valores no comércio. A classe das cisteína-proteases é a mais frequentemente utilizadas para o amaciamento de vários tipos de carnes, no sítio ativo dessas proteases estão presentes os aminoácidos cisteína, ácido aspártico e histidina que irão atuar nas extremidades ou no meio interno das ligações peptídicas. As cisteínas de origem vegetal são as mais preferidas, entre elas estão a papaína (EC3.4.22.2), actinidina (EC3.4.22.14), bromelaína (EC3.4.22.32), zingiberina, (EC3.4.22.67) e ficain (EC3.4.22.3) (BOTINESTEAN et al., 2021; CRUZ et al., 2020; GAGAOUA et al., 2020; JUN-HUI et al., 2020; LI et al., 2021; ZHU et al., 2018).

Para que ocorra a modificação na estrutura da carne essas enzimas irão desestruturar, principalmente, as proteínas miofibrilares e as sarcoplasmáticas (GAGAOUA et al., 2020). O uso de proteases vegetais em carne de aves de corte foi o objetivo da pesquisa realizada por Cruz et al. (2019) a fim de determinar a maciez, fragmentação miofibrilar e rendimento póscozimento do peito de frango. As proteases foram extraídas do rizoma de Zingiber officinale Roscoe (gengibre) oriundos da Região Sudeste do Brasil, local também de onde foram obtidos os cortes de peito de frango (espécie não informada). Com o extrato bruto foi realizada a atividade proteolítica da enzima através de método colorimétrico. Para avaliação da ação de degradação da protease uma concentração de $5 \%$ do extrato foi injetada na carne de frango, e 
com isso foram determinados o índice de fragmentação miofibrilar (MFI), o comprimento dos fragmentos miofibrilares (MFL) e o comprimento do sarcômero. A maciez foi avaliada por método de força de cisalhamento mecânico e a perda de peso foi calculada comparando o peso inicial e o final. Como resultados a pesquisa demonstrou, 76.05 de MFI, $4.54 \mu \mathrm{m}$ de MFL e 1.35 de comprimento do sarcômero $(\mu \mathrm{m})$. Isso demonstra que a aplicação de proteases obtidas do gengibre foi capaz de degradar as miofibrilas (Figura 04), o que levou a redução da força de cisalhamento e não houve redução significativa no rendimento do peito de frango após o cozimento.

Figura 04: Fragmentação da miofibrila e redução do MFL.
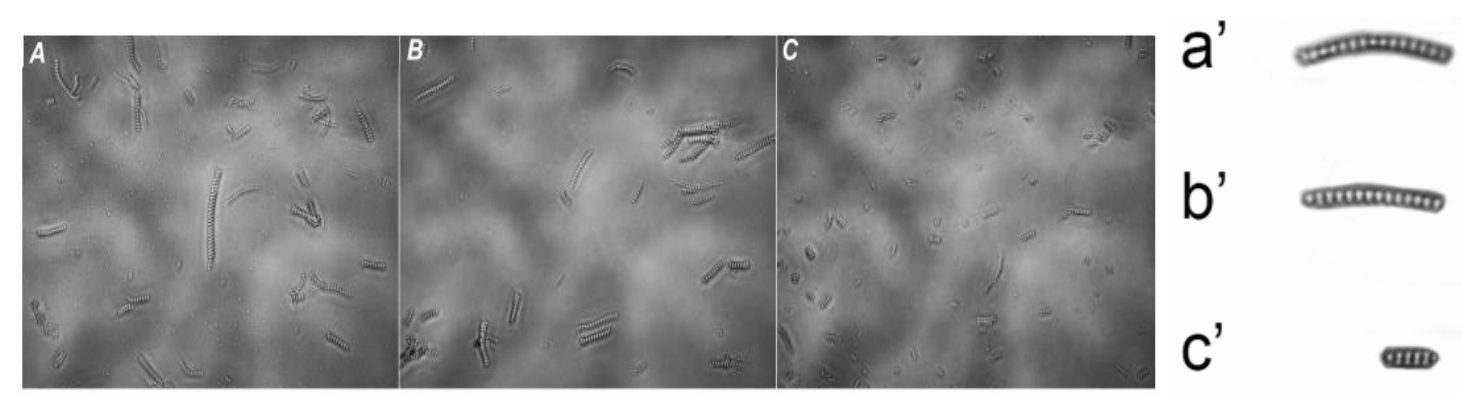

Fonte: Adaptado de Cruz et al. (2019).

Em alguns processos a aplicação de proteases para fins de amaciamento de carnes ocorre sobre uma proteína presente no tecido conjuntivo, o colágeno. Formado por uma tripla hélice de proteínas, o colágeno é uma proteína fibrosa que proporciona sustentação, elasticidade e resistência a várias estruturas, principalmente aos músculos o que caracteriza uma rigidez maior a carne que pode ser desfeita a partir da ação de clivagem de proteases colagenolíticas (EC 3.4.21.-) sobre o colágeno (RODRÍGUEZ et al., 2018). Sorapukdee et al. (2020) realizou um estudo sobre a capacidade de microrganismos proteases com potencial na degradação do colágeno. Na pesquisa os autores realizaram uma triagem sobre a capacidade de 400 espécies de Bacillus sp. produzirem proteases com atividade colagenolítica. Entre essas espécies estudadas apenas 20 foram capazes de produzir protease com atividade colagenolítica acima de 0,5 U/mL. As espécies Bacillus subtilis e B. siamensis foram as escolhidas para terem a capacidade colagenolítica de suas enzimas testadas sobre o tendão de Aquiles, o colágeno intramuscular e a proteína miofibrilar de carne bovina. As metodologias realizadas demonstraram que as proteases colagenolíticas produzidas por B. subtilis e B. siamensis foram capazes de degradar tanto o colágeno como a elastina de todas as estruturas utilizadas, comprovando o sucesso na aplicação de proteases produzidas por essas bactérias no amaciamento de carnes. Oliveira et al., (2016) realizaram um levantamento sobre a presença de 
proteases em várias espécies de peixes, crustáceos, poríferos e equinodermos. As proteases observadas pelos autores eram do tipo metalo e serinocolagenases. As metalocolagenases são capazes de degradar a matriz extracelular do colágeno sendo elas, as colagenases verdadeiras que clivam a tripla hélice do colágeno e as gelatinases hidrolisam os colágenos desnaturados e as gelatinas. Já as serinocolagenases são capazes de degradar os tipos I, II e III da tripla hélice do colágeno. Pelo autor foram citados os gêneros Novoden sp., Pagrus sp., Rhopaloeides sp., Raja sp., Gadus sp., Carcinus sp., Pseudopleuronectes sp., Thunnus sp., Macrobrachium sp., Scomber sp., Chionoecetes sp. Nesses indivíduos e vários outros oriundos do pescado normalmente as proteases são encontradas em suas vísceras digestivas, nos músculos, na cabeça, nas barbatanas, na cauda e vísceras reprodutivas. Os autores também perceberam que no ramo alimentício essas proteases são empregadas na musculatura de peixes auxiliando nas etapas de remoção da pele e extração do colágeno.

\section{Panificação}

No setor de panificação as proteases mais utilizadas são de fonte vegetal e microbiológicas. As ações dessas proteases consistem na degradação, por hidrólise, da proteína glúten, ele está presente em vários grãos e sua finalidade de uso na panificação visa a obtenção de uma massa consistente e viscosamente elástica que proporcione a retenção de ar (DAHIYA et al., 2020). O glúten é constituído pela junção de outras duas proteínas: a glutelina e a gliadina, a rede formada pelas ligações de dissulfeto e caso o número dessas ligações for superior ao ideal ocorre uma dificuldade da manipulação da massa devido à alta rigidez. Uma alternativa para a solução desse problema é o emprego de proteases durante a fermentação da massa, onde as enzimas irão hidrolisar as ligações peptídicas do glúten, dando mais maciez e menos densidade a massa o que facilita seu manuseio e melhora sua aparência (JAYAWARDANA et al., 2021). A liberação dos grupos carboxila (COOH) e amina $\left(\mathrm{NH}_{2}\right)$ pelas hidrólises realizadas nas extremidades $\mathrm{C}$ - e N-terminal acaba agregando ao sabor da massa a partir do momento em que tais compostos irão reagir com açúcar presente no meio, um efeito resultante da Reação de Maillard, onde sob calor os aminoácidos e o açúcar interagem dando cor e sabor a massa (FRANCISQUINI et al., 2017).

Sarabhai et al. (2021) estudou a aplicação de enzimas, entre elas as proteases, sobre as características de pão feito a partir de milho. Os pães foram preparados com Setaria parviflora (milho rabo de raposa), 0,05 e 0,1g / 100g de cada enzima (inclusive proteases) e outros ingredientes. Após assados, os pães foram triturados e liofilizados para serem submetidos a 
estudos de propriedades reológicas, colagem da farinha no pão, as características da massa, textura e outros. Os autores em seus resultados demonstraram que, a adição de proteases diminuiu a viscosidade da massa de $404 \mathrm{~Pa} \cdot \mathrm{s}$ para $154 \mathrm{~Pa} \cdot \mathrm{s}$, o que gerou uma maior elasticidade a massa; a matriz proteica que envolve os grânulos de amido foi degradada pela ação de proteases; o ângulo de fase $(\delta)$ foi diminuído pela protease; a adição de proteases também melhorou a aceitabilidade do produto, seu aroma e sabor. Após o estudo foi concluído que, entre as enzimas protease, glicose oxidase e xilanase as de atividade proteolíticas foram eleitas as melhores para o melhoramento do pão de forma feio com milho rabo de raposa (Figura 05).

Figura 05: Pão de milho rabo de raposa sem glúten com diferentes concentrações de enzimas. A controle, B - glicose oxidase $(0,05 \mathrm{~g} / 100 \mathrm{~g}), \mathrm{C}$ - glicose oxidase $(0,1 \mathrm{~g} / 100 \mathrm{~g}), \mathrm{D}$ - xilanase $(0,05 \mathrm{~g} / 100 \mathrm{~g}), \mathrm{E}$ - xilanase $(0,1 \mathrm{~g} / 100 \mathrm{~g}), \mathrm{F}$ - proteases $(0,05 \mathrm{~g} / 100 \mathrm{~g}), \mathrm{G}$ - protease $(0,1 \mathrm{~g} / 100 \mathrm{~g})$ com base no peso da farinha.

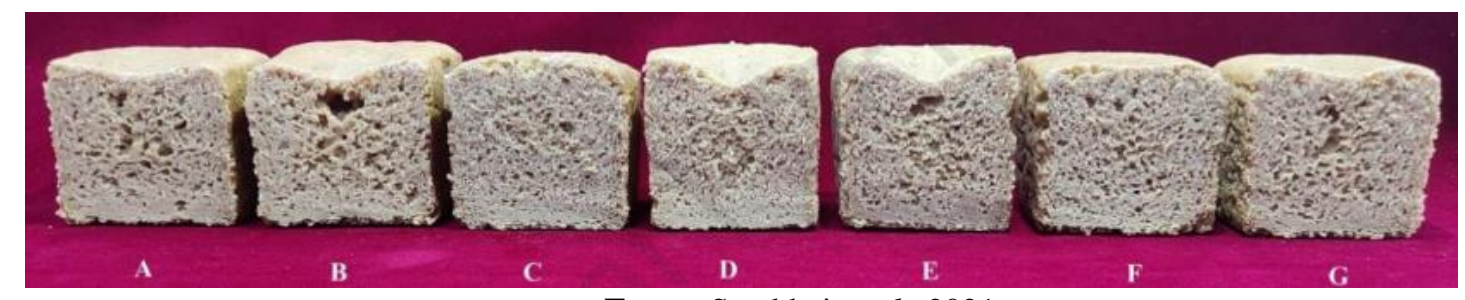

Fonte: Sarabhai et al., 2021.

\section{Laticínios}

No setor de fabricação dos mais variados tipos de queijos a proteases protagonizam alguns eventos do processo como a coagulação e a maturação do queijo. O objetivo da coagulação no processamento de queijos é a concentração do leite e a retenção de gorduras, frequentemente para esses processos é utilizado um composto denominado coalho, que tem como componentes as proteases, quimosina e pepsina (ARBITA et al., 2020).

Antigamente conhecida como "renina (EC 3.4.4.3.)" a quimosina (EC 3.4.23.4) pode ser extraída da secreção estomacal de ovinos, plantas ou microrganismos. Assim que extraída a quimosina encontra-se em seu estado inativo (quando em $\mathrm{pH}$ neutro) e posteriormente (em meio ácido) se transforma na quimosina que tem atividade proteolítica ativa. A quimosina age no processo de coagulação do leite, sua ação é sobre a caseína desestabilizando suas micelas a fim de romper a $\kappa$-caseína, mais precisamente onde estão os aminoácidos fenilalanina o metionina (Figura 06). A pepsina, por sua vez, possui uma atividade menos específica, clivando qualquer ligação que apresente resíduos de valina, fenilalanina, leucina ou tirosina. Após a coagulação existem várias outras etapas no processo de fabricação do queijo, uma delas é a etapa de maturação onde ocorre várias reações químicas sobre o coágulo, entre elas a proteólise, 

ALURU \& SUKUMARAN, 2021).

Figura 06: Ação das proteases sobre a caseína para coagular o leite durante a fabricação de queijos.

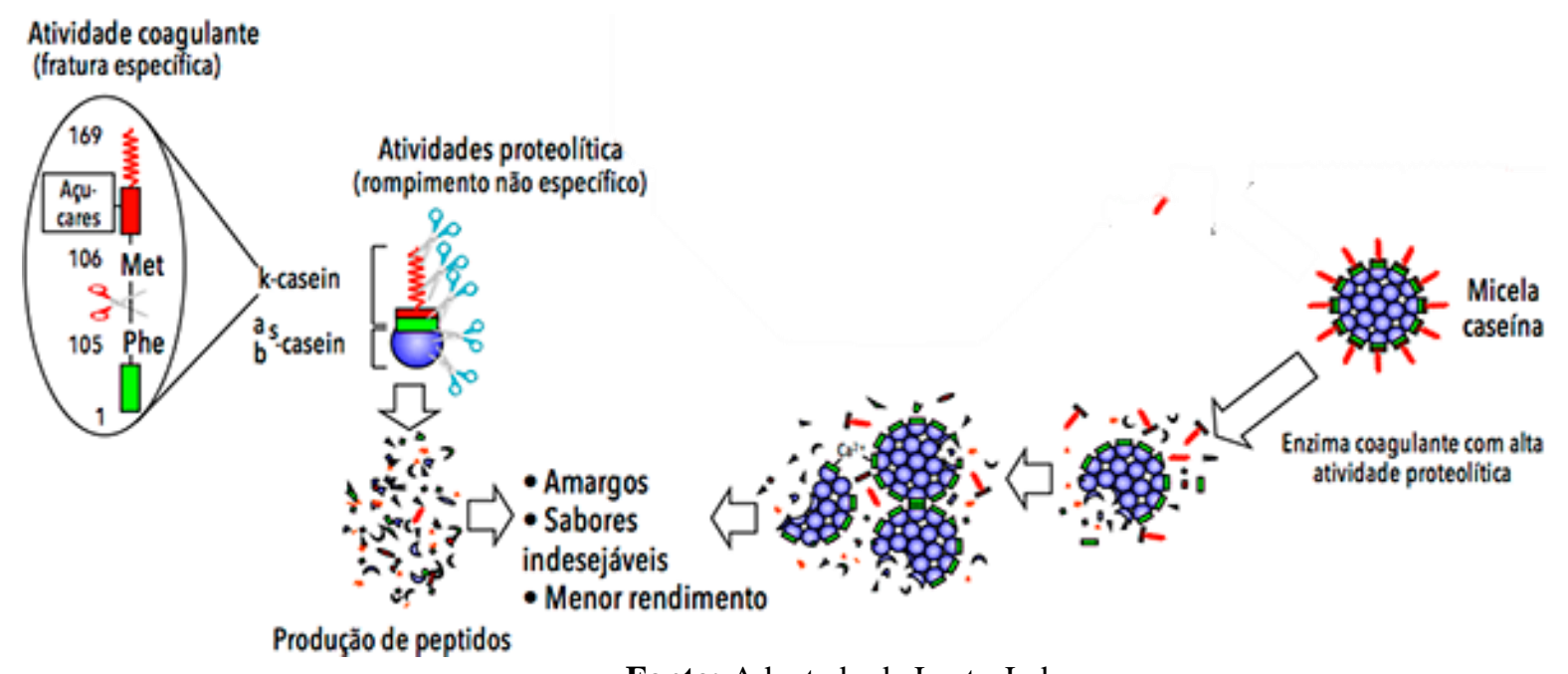

Fonte: Adaptado de Lacto-Lab.

Paludetti et al. (2020) avaliou os efeitos da aplicação de proteases fúngicas na produção de queijo do tipo cheddar. No leite foram adicionadas respectivas quantidades de 0,15 e 0,60 U/L de proteases produzida por Pseudomonas fluorescens. Após $48 \mathrm{~h}$ de armazenamento do leite a $4^{\circ} \mathrm{C}$ o queijo foi fabricado. Foi constatada alta atividade proteásica durante todo o processo de armazenamento, porém durante a fabricação do queijo a atividade diminuiu, o que pode ter sido influenciado pela diferença de $\mathrm{pH}$ entre os dois processos. A enzima degradou duas proteínas a $\beta$-caseína e a $\kappa$-caseína, porém não foram afetados o rendimento do queijo e a recuperação de gordura e proteínas. Comparados com o queijo controle (sem adição de proteases), os queijos com ambas as concentrações supracitadas demonstraram altos níveis de aminoácidos livres. Com isso, a pesquisa comprovou que as proteases podem modificar os aspectos do queijo e também podem aumentar seus valores nutricionais.

\section{Cervejas}

A produção de cervejas data aproximadamente 2100 a.C, acredita-se que a produção da bebida foi um acidente, mas que deixava o povo Sumério feliz. Ao passar de geração em geração e entre várias etnias, a cerveja hoje é uma das bebidas mais consumidas no mundo (SILVA \& PINHEIRO, 2018). O processo de cerveja inclui cerca de doze etapas no qual durante um deles ocorre a aplicação de proteases, na maturação. Logo após a etapa de 
fermentação ocorre a maturação, a etapa visa o armazenamento do produto sob baixas temperaturas. É um momento que pode demorar dias ou semanas dependendo do tipo de cerveja, visando a clarificação e a maturação do sabor. A presença de um grande quantitativo de leveduras faz com que o líquido fique muito turvo. Só uma filtração não é o suficiente para a diminuição da turbidez, e a partir disso são aplicadas as proteases. As enzimas com atividade proteolítica irão na hidrólise de peptídeos impedindo que eles se insolubilizem e formem a turvação (PIMENTA et al., 2020). Apesar de ser uma das bebidas mais consumidas no mundo, algumas pessoas evitam consumi-las devido ao seu teor de glúten. Assim como na panificação na indústria cervejeira, as proteases também podem ser aplicadas com o intuito de degradação do glúten (ROTOLO, 2019). Benucci et al. (2019) testou o uso da prolil endopeptidase de origem microbiana na redução do teor de glúten de cervejas. Proteases produzidas pelo fungo filamentoso Aspergillus niger foram imobilizadas em grânulos a quitosana e adicionadas a cerveja com malte de cevada. A imobilização aumentou a estabilidade térmica da protease, a quantidade de $728 \mathrm{~mL} / \mathrm{min}$ foi o suficiente para diminuir o teor de glúten de $65 \mathrm{mg} / \mathrm{kg}$ para 19 $\mathrm{mg} / \mathrm{kg}$ após 9 horas de vazão e para $15 \mathrm{mg} / \mathrm{kg}$ após 10h de tratamento. Demonstrando assim o sucesso da aplicação de proteases também na redução da quantidade de glúten na cerveja.

\section{CONCLUSÕES}

De fato, é notório o tão quanto a ação de clivagem através de hidrólise faz das proteases as enzimas mais exploradas comercialmente. Entre os inúmeros setores industriais existentes, os setores de bebidas e alimentos são os que mais utilizam essas enzimas durante seus processos de fabricação, e essa posição não só segue a mesma durante os últimos cinco anos como está prevista para seguir intacta nos próximos seis anos. Buscando a melhoria de seus produtos, as indústrias de carnes utilizam as proteases principalmente no seu amaciamento o que consequentemente leva a mudanças do aspecto, sabor e na consistência das carnes, sendo essas mudanças cobiçadas a agregar valores a certos tipos de carnes que geralmente não são tão valorizadas devido a suas características. Sem as proteases os processos de fabricação de laticínios seriam incompletos já que as etapas de coagulação e a maturação do queijo, por exemplo, é totalmente depende da ação de determinadas enzimas proteolíticas. Mas também, o setor de laticínios faz uso das proteases afim de aumentar os valores nutricionais de seus produtos. As industriais de panificação e cervejas utilizam as proteases com um foco comum, a diminuição ou até mesmo zerar a quantidade da proteína glúten nos produtos, visto que tal proteína pode causar algumas problemáticas a saúde humana como o excesso de peso e males 
ao intestino delgado. Todas essas aplicações biotecnológicas das proteases ressaltam ainda mais

o seu recorrente uso industrial visando a produção e melhoramento de bebidas e alimentos, confirmando também a importância das inúmeras pesquisas científicas que comprovam as ações biotecnológicas das proteases e claro a necessidade de mais pesquisas descrevendo novas fontes de peptidases, suas características e seus potenciais nos mais variados setores industriais.

\section{REFER̂̂ENCIAS}

ARBITA, A. A. et al. Extraction, partial purification and characterization of proteases from the red seaweed Gracilaria edulis with similar cleavage sites on $\kappa$-casein as calf rennet. Food chemistry, v. 330, p. 127324, 2020.

ALUDETTI, L. F. et al. Effect of Pseudomonas fluorescens proteases on the quality of Cheddar cheese. Journal of Dairy Science, v. 103, n. 9, p. 7865-7878, 2020.

AQUINO, C. M. Efeito das enzimas naturais e artificiais no amaciamento da carne ovina. 2017. 111 f. Dissertação (Mestrado em Tecnologia de Alimentos) - Instituto Federal de Educação, Ciência e Tecnologia do Ceará, Limoeiro do Norte.

BENUCCI, I. et al. Prolyl endopeptidase from Aspergillus niger immobilized on a food-grade carrier for the production of gluten-reduced beer. Food Control, v. 110, p. 106987, 2020.

BOTINESTEAN, C. et al. The influence of the interaction of sous-vide cooking time and papain concentration on tenderness and technological characteristics of meat products. Meat Science, p. 108491, 2021.

CHEN, Y. et al. Sesame water-soluble proteins fraction contains endopeptidases and exopeptidases with high activity: a natural source for plant proteases. Food Chemistry, p. 129519, 2021.

CHIMBEKUJWO, K. I; JA'AFARU, M. I.; ADEYEMO, O. M. Purification, characterization and optimization conditions of protease produced by Aspergillus brasiliensis strain BCW2. Scientific African, v. 8, p. e00398, 2020.

CRUZ, P. L. et al. Effect of proteases from ginger rhizome on the fragmentation of myofibrils and tenderness of chicken breast. LWT, v. 120, p. 108921, 2020.

DA SILVA, R. R. Bacterial and fungal proteolytic enzymes: production, catalysis and potential applications. Applied Biochemistry and Biotechnology, v. 183, n. 1, p. 1-19, 2017.

DAHIYA, S. et al. A review on biotechnological potential of multifarious enzymes in bread making. Process Biochemistry, 2020.

ELLEUCH, J. et al. Extracellular neutral protease from Arthrospira platensis: Production, optimization and partial characterization. International Journal of Biological Macromolecules, v. 167, p. 1491-1498, 2021. 
EL-YAMANY, M. F. et al. Gamma irradiated protease from Echis pyramidum venom: A promising immunogen to improve viper bites treatment. Toxicon, v. 188, p. 108-116, 2020.

ENZYME. Search by enzyme class. Disponível em: (https://enzyme.expasy.org/cgibin/enzyme/enzyme-search-cl?2). Acesso em 20 mar. 2021.

FRANCISQUINI, J. A. et al. Reação de maillard: uma revisão. Revista do Instituto de Laticínios Cândido Tostes, v. 72, n. 1, p. 48-57, 2017.

GAGAOUA, M. et al. Artificial meat tenderization using plant cysteine proteases. Current Opinion in Food Science, 2020.

GRAND VIEW RESEARCH. Enzymes Market Size, Share \& Trends Analysis Report By Application (Industrial Enzymes, Specialty Enzymes), By Product (Carbohydrase, Proteases, Lipases), By Source, By Region, And Segment Forecasts, 2020 - 2027. 2019. Disponível em: https://www.grandviewresearch.com/industry-analysis/enzymes-industry. Acesso em 21 mar. 2021.

GUO, Y. et al. Characterization of an intracellular aspartic protease (PsAPA) from Penicillium sp. XT7 and its application in collagen extraction. Food Chemistry, v. 345, p. 128834, 2021

HOSPITAL ISRAELITA ALBERT EINSTEIN. Intolerância à lactose: cuidados com a alimentação. Disponível em: https://vidasaudavel.einstein.br/intolerancia-a-lactose-cuidadoscom-a-alimentacao/. Acesso: 23 mar 2021.

IBAÑEZ, I. L. et al. In vivo tumor growth inhibition by Solanum tuberosum aspartic protease 3 (StAP3) treatment. Bioorganic \& Medicinal Chemistry Letters, p. 127959, 2021.

IQBAL, A. et al. Partial purification and characterization of serine protease produced through fermentation of organic municipal solid wastes by Serratia marcescens A3 and Pseudomonas putida A2. Journal of Genetic Engineering and Biotechnology, v. 16, n. 1, p. 29-37, 2018.

JAYAWARDANA, I.A. et al. The kiwifruit enzyme actinidin enhances the hydrolysis of gluten proteins during simulated gastrointestinal digestion. Food Chemistry, v. 341, p. 128239, 2021.

JUN-HUI, X. et al. The mechanistic effect of bromelain and papain on tenderization in jumbo squid (Dosidicus gigas) muscle. Food Research International, v. 131, p. 108991, 2020.

KERMASHA, S.; ESKIN, M. N. Enzymes. In: KERMASHA, S.; ESKIN, M. N. Enzymes Novel Biotechnological Approaches for the Food Industry. 1 ed. Cambridge: Academic Press, 2021. cap 2, 2021, páginas 15-44.

KUNIYOSHI, A. K. et al. Experimental antivenom against serine proteases from the Bothrops jararaca venom obtained in mice, and its comparison with the antibothropic serum from the Butantan Institute. Toxicon, v. 169, p. 59-67, 2019.

LACTO-LAB. Coagulante Liquido Ultra. Disponível em: http://www.lactolab.com/coagulante-liquido-ultra.html. Acesso em 23 mar. 2021. 
LANGENEGGER, N. et al. Identification of a precursor processing protease from the spider Cupiennius salei essential for venom neurotoxin maturation. Journal of Biological Chemistry, v. 293, n. 6, p. 2079-2090, 2018.

LI, D. et al. Effects of ficin, high pressure and their combination on quality attributes of postrigor tan mutton. LWT, v. 137, p. 110407, 2021.

LIU, H. et al. Functional characterization of two clip-domain serine proteases in the swimming crab Portunus trituberculatus. Fish \& shellfish immunology, v. 89, p. 98-107, 2019.

LÓPEZ, I. A. H. et al. Characterization of digestive enzymes during early ontogeny of white Snook (Centropomus viridis). Aquaculture, v. 535, p. 736399, 2021.

MEROPS. Families of Proteolytic Enzymes. Disponível em: https://www.ebi.ac.uk/merops/cgi-bin/family_index?type=P. Acesso em 20 mar. 2021.

MUKHIA, S.; KUMAR, A.; KUMAR, R. Generation of antioxidant peptides from soy protein isolate through psychrotrophic Chryseobacterium sp. derived alkaline broad temperature active protease. LWT, v. 143, p. 111152, 2021.

MUSIDLAK, O. Plant latex proteins and their functions. In: NAWROT, R. Advances in Botanical Research.: Látex, laticíferos e seus componentes moleculares de funções a possíveis aplicativos. Vol. 93. Amsterdã: Elsevier, 2020. Cap. 3, pag. 55-97.

MURI, E. M. F. Proteases virais: importantes alvos terapêuticos de compostos peptideomiméticos. Química Nova, v. 37, n. 2, p. 308-316, 2014.E

NELSON, D. L.; COX, M. M. Princípios de Bioquímica de Lehninger. 7ed. Artmed Editora, 2018.

NEUMANN, C. et al. Development of a generic high-throughput screening assay for profiling snake venom protease activity after high-resolution chromatographic fractionation. Toxicon, $\mathrm{v}$. 178, p. 61-68, 2020.

OLIVEIRA, V. et al. Colagenases do pescado e suas aplicações industriais. Pubvet, v. 11, p. 207-312, 2016.

OLIVEIRA, V. M. et al. Separation and partial purification of collagenolytic protease from peacock bass (Cichla ocellaris) using different protocol: Precipitation and partitioning approaches. Biocatalysis and Agricultural Biotechnology, v. 24, p. 101509, 2020.

OSMOLOVSKIY, A. A. et al. Vermiculite as a new carrier for extracellular protease production by Aspergillus spp. under solid-state fermentation. Biotechnology Reports, v. 29, p. e00576, 2021.

PATYSHAKULIYEVA. Fungal Proteases: Current and Potential Industrial Applications. Reference Module in Life Sciences. 2021.

PIMENTA, L. B. et al. A história e o processo da produção da cerveja: uma revisão. Cadernos de Ciência \& Tecnologia, v. 37, n. 3, p. 26715, 2020. 
RAJAGOPALAN, A.; ALURU, V.; SUKUMARAN, B. O. Characterisation of hydrolysate for identifying initial peptide cleavage site of $\kappa$-casein by milk coagulating Wrightia tinctoria serine proteases. International Dairy Journal, v. 115, p. 104934, 2021.

RODRÍGUEZ, M. I. A.; RODRIGUEZ, L. G. B.; SÁNCHEZ, M. L. Collagen: A review on its sources and potential cosmetic applications. Journal of Cosmetic Dermatology, v. 17, n. 1, p. 20-26, 2018.

RODWELL, V. W. et al. Bioquímica Ilustrada de Harper-31. McGraw Hill Brasil, 2021.

ROTOLO, T. Cultura cervejeira: breve história da cerveja artesanal no Brasil. Revista Ingesta, v. 1, n. 2, p. 141-142, 2019.

SAINTBIER. A história da cerveja. Disponível em: http://www.saintbier.com/historiacerveja. Acesso em 24 mar. 2021.

SARABHAI, S.; TAMILSELVAN, T.; PRABHASANKAR, P. Role of enzymes to improve gluten-free foxtail corn bread: It has an effect on the properties of quality, texture, rheology and collage. LWT, v. 137, p. 110365, 2021.

SARKAR, G.; SUTHINDHIRAN, K. Extraction and characterization of alkaline protease from Streptomyces sp. GS-1 and its application as dehairing agent. Biocatalysis and Agricultural Biotechnology, v. 25, p. 101590, 2020.

SHAFIQUE, T. et al. Screening, selection and development of Bacillus subtilis apr-IBL04 for hyper production of macromolecule alkaline protease. Saudi Journal of Biological Sciences, v. 28, n. 2, p. 1494-1501, 2021.

SILVA, A. V. et al. Partial purification of fibrinolytic and fibrinogenolytic protease from Gliricidia sepium seeds by aqueous two-phase system. Biocatalysis and Agricultural Biotechnology, v. 27, p. 101669, 2020.

SILVA, J. C. et al. Extraction of collagenolytic enzyme from fish viscera by phase partitioning (PEG/citrate) and its potential for industrial application. Boletim do Instituto de Pesca, v. 46, n. 4, 2021.

SILVA, L. H.; PINHEIRO, B. C. S. Produções científicas do antigo Egito: um diálogo sobre Química, cerveja, negritude e outras coisas mais. Revista Debates em Ensino de Química, v. 4, n. 1, p. 5-28, 2018.

SILVA, M. A. et al. Digestive enzymes profile of the midgut gland of juvenile painted river prawn (Macrobrachium carcinus). Aquaculture Reports, v. 18, p. 100507, 2020.

SILVA, M. Z. R. et al. Biotechnological potential of a cysteine protease (CpCP3) from Calotropis procera latex for cheesemaking. Food chemistry, v. 307, p. 125574, 2020.

SORAPUKDEE, S. et al. Collagenolytic proteases from Bacillus subtilis B13 and B. siamensis S6 and their specificity toward collagen with low hydrolysis of myofibrils. LWT, v. 126, p. 109307, 2020. 
URS, A. P. et al. Thrombin-like serine protease, antiquorin from Euphorbia antiquorum latex induces platelet aggregation via PAR1-Akt/p38 signaling axis. Biochimica et Biophysica Acta (BBA)-Molecular Cell Research, v. 1868, n. 3, p. 118925, 2021.

VIA FARMA. Literatura técnica: Zoomzyme Glu10 blend de enzimas para o glúten. Disponível em: https://viafarmanet.com.br/zoomzyme/\#: :text=Zoomzyme\%20Glu10\%C2\%AE\%20\%C3\%A 9\%20uma,\%C3\%A0s\%20existentes\%20hoje\%20no\%20mercado. Acesso em 22 mar 2021.

YANG, X. et al. Assessment of the production of Bacillus cereus protease and its effect on the quality of ultra-high temperature-sterilized whole milk. Journal of Dairy Science, 2021.

ZHU, X. et al. Actinidin pretreatment and sous vide cooking of beef brisket: Effects on meat microstructure, texture and in vitro protein digestibility. Meat science 2018, 145: 256-65.

WANG, X. et al. Comparative proteome analysis of matured dry and germinating Moringa oleifera seeds provides insights into protease activity during germination. Food Research International, v. 136, p. 109332, 2020. 